
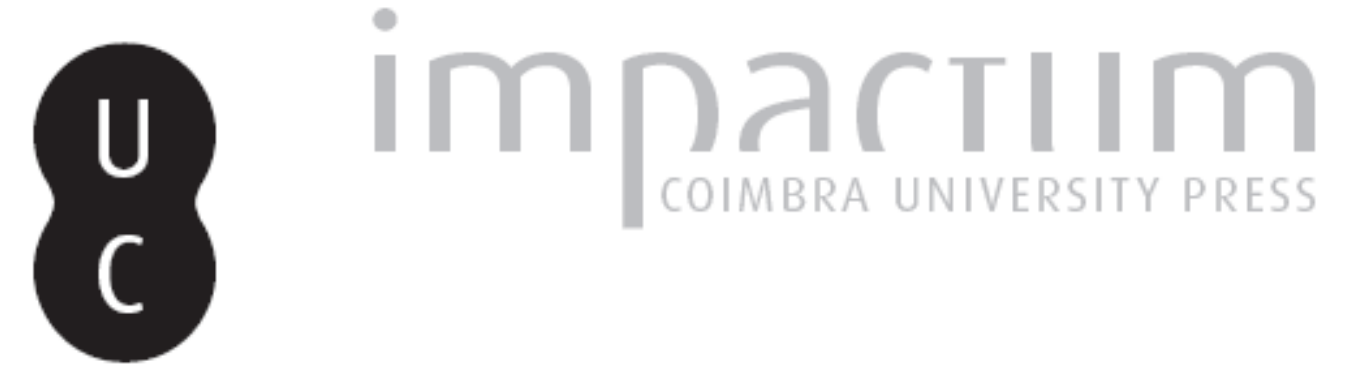

\title{
Tímoria e páthos em Medeia, de Eurípedes
}

Autor(es): $\quad$ Timbó, Margarida Pontes; Oliveira, Ângelo Bruno Lucas de

Publicado por: Sociedade Brasileira de Estudos Clássicos

URL persistente:

URI:http://hdl.handle.net/10316.2/35779

DOI:

DOI:http://dx.doi.org/10.14195/2176-6436_22-2_5

Accessed : $\quad$ 26-Apr-2023 14:18:40

A navegação consulta e descarregamento dos títulos inseridos nas Bibliotecas Digitais UC Digitalis, UC Pombalina e UC Impactum, pressupõem a aceitação plena e sem reservas dos Termos e Condições de Uso destas Bibliotecas Digitais, disponíveis em https://digitalis.uc.pt/pt-pt/termos.

Conforme exposto nos referidos Termos e Condições de Uso, o descarregamento de títulos de acesso restrito requer uma licença válida de autorização devendo o utilizador aceder ao(s) documento(s) a partir de um endereço de IP da instituição detentora da supramencionada licença.

Ao utilizador é apenas permitido o descarregamento para uso pessoal, pelo que o emprego do(s) título(s) descarregado(s) para outro fim, designadamente comercial, carece de autorização do respetivo autor ou editor da obra.

Na medida em que todas as obras da UC Digitalis se encontram protegidas pelo Código do Direito de Autor e Direitos Conexos e demais legislação aplicável, toda a cópia, parcial ou total, deste documento, nos casos em que é legalmente admitida, deverá conter ou fazer-se acompanhar por este aviso.

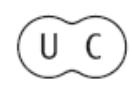




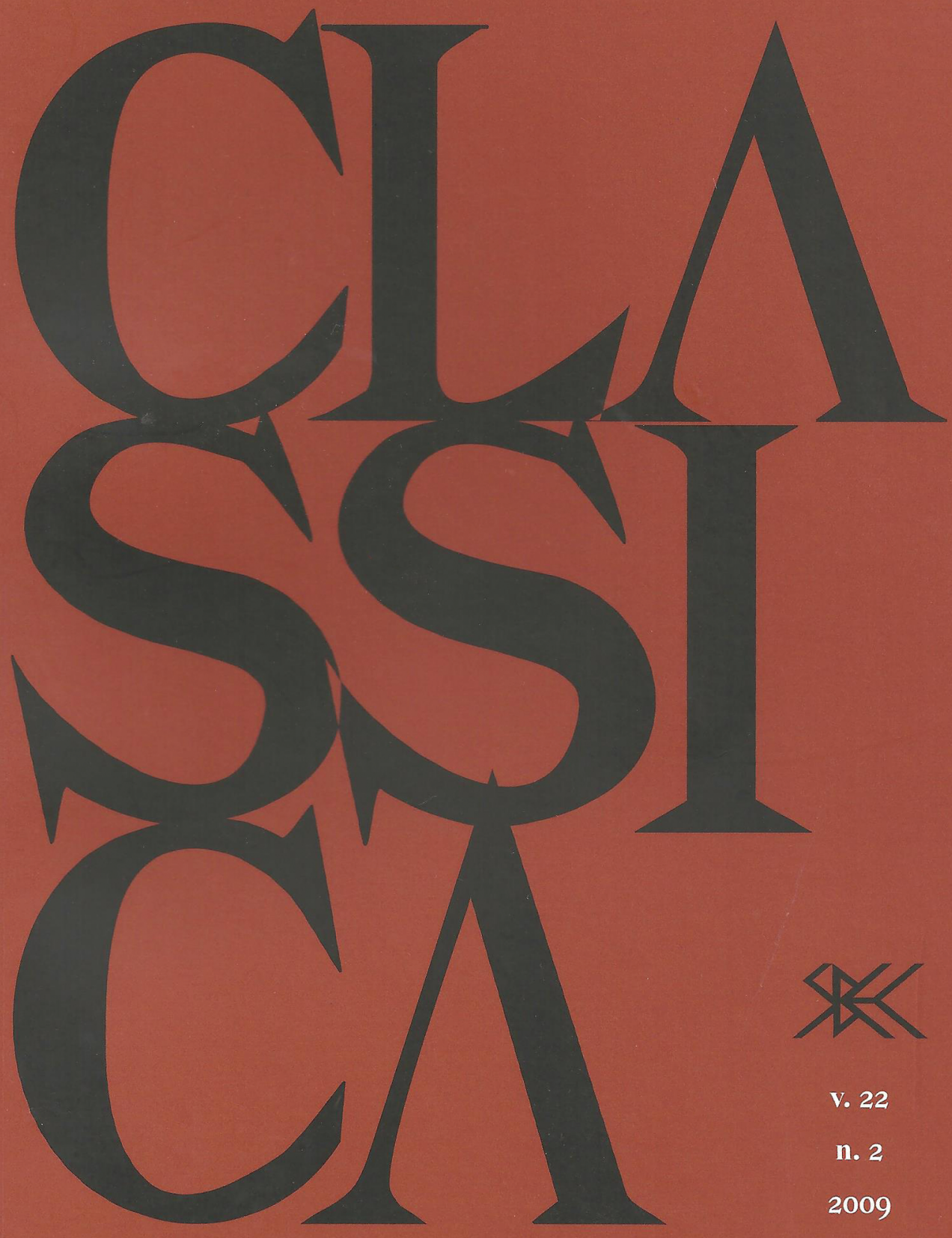




\title{
Tímoria e páthos em Medeia, de Eurípedes
}

\author{
Margarida Pontes TimbÓ \\ Ângelo Bruno Lucas de Oliveira \\ Universidade Federal do Ceará \\ Brasil
}

Resumo. Este texto apresenta algumas considerações acerca da tímoria (a vingança) e do páthos (o sofrimento), na tragédia Medeia, de Eurípedes, escrita por volta do século V a.C. A imagem da Medeia imortalizada para os leitores é aquela mulher melancólica, que sofre devido ao abandono do homem amado; monstruosa e vingativa, atinge o ápice de seu desespero quando mata os próprios filhos para ferir o esposo infiel. $\mathrm{O}$ ciúme serve de mote ao filicídio, gerando a tímoria e, em consequência, o páthos. Rejeitada pelo amado, Medeia simboliza a mulher impulsiva, passional, que castiga drasticamente o esposo pelo perjúrio cometido. Medeia trágica foge aos padrões da mulher ateniense da época de Eurípedes; tal fato sugere que ela não seria o tipo de esposa ideal. A tragédia em foco prenuncia ao ateniense do período sua possível condição ao tornar-se grego: encontrar um caminho inverso ao da glória, o risco de tornar-se bárbaro como Medeia, reflexo da vingança e do sofrimento diante de infortúnios.

Palavras-chave. Medeia; tragédia; vingança; sofrimento.

A pergunta que se faz sempre que se recorre à tragédia de Eurípedes é: quem foi a heroína Medeia? As possíveis respostas invariavelmente a associariam a adjetivos tais como ambígua, traiçoeira, apaixonada, cruel, e, sobretudo, misteriosa. Essa categorização, no entanto, não abarca a infinidade de nuanças de que se compõe essa personagem.

$\mathrm{Na}$ verdade, costuma-se observar, em muitas leituras, que a Medeia trágica apresenta as características de uma feiticeira, mulher apaixonada, esposa impiedosa e mãe desumana. No entanto, até que ponto o leitor pode conceber a personagem desta forma? Talvez ela tenha muito mais para acrescentar à sociedade contemporânea, haja vista que ela expõe alguns dos sentimentos humanos mais nefandos, tais como o ciúme, o ódio, a ira, a vingança e, por conseguinte, o sofrimento que advém com essa última.

Emails: guidinhapontes@yahoo.com.br e angelus_brunus@hotmail.com

Programa de Pós-Graduação em Letras. Mestrado em Literatura Comparada. 
No tocante à composição do gênero trágico, na Arte Poética, Aristóteles lembra que a tragédia 'deve imitar casos que suscitem temor e piedade' ${ }^{1}$. Existiriam, de acordo com o filósofo, quatro possibilidades para o desfecho trágico: (i) o justo passa da felicidade para a infelicidade, ou (ii) da infelicidade para a felicidade; (iii) o perverso passa da felicidade para a infelicidade, ou (iv) da infelicidade para a felicidade. A partir de um olhar panorâmico sobre as tragédias clássicas, porém, pode-se inferir que existe tanto uma razão primária para se excluir o herói perverso que passa ou da felicidade para a infelicidade, ou da infelicidade para a felicidade - que é o não suscitar, em qualquer dos dois casos, as emoções que são próprias da tragédia - quanto uma razão secundária para se excluir a passagem da infelicidade para a felicidade - que é a sua não-conformidade com a filantropia.

A hamartía, isto é, o erro, não representa uma parte do caráter do herói trágico, mas sim uma parte estrutural do mito complexo; é o correlato da anagnórisis (reconhecimento). Aristóteles não menciona a anagnórisis juntamente com a peripécia, o reconhecimento e a catástrofe, talvez porque ela pode residir fora da própria ação dramática, como no Édipo, em que o 'erro' acontece antes da ação dramática. A hamartía, portanto, fornece a plausível razão para a futura glória do herói.

Pode-se dizer assim que a Medeia trágica é bem diversa da Medeia mítica que a inspirou e que aponta quase para uma releitura desta. Há indícios de que a Medeia mítica teria sido uma mulher xena, ou persa, cujas características se assemelham às da Medeia trágica. A versão do mito de Medeia criada por Eurípedes poderia ser, também, uma releitura da lenda de Procne, que também se vingara da traição do marido matando o filho Ítis, que tivera com o esposo infiel ${ }^{2}$; tal mito também é relatado no texto das Metamorfoses, de Ovídio. Sejam quais forem as fontes a que Eurípedes volveu para a construção da sua tragédia, todas elas têm um traço em comum: o assassinato de consanguíneos, o que, na visão de Aristóteles, caracterizaria os mitos mais trágicos.

Assim sendo, por possuir uma forte inspiração dos mitos, as tragédias construíram uma ressignificação dos mesmos, reelaborando alguns aspectos da narrativa mítica. O poder do mito só faz sentido se o autor não for fiel a ele. Logo, as muitas versões de um mito são, na verdade, o próprio mito que sobrevive.

${ }^{1}$ Aristóteles, Os Pensadores 2: Ética a Nicômaco - Poética, seleção de textos de José Américo Motta Pessanha, São Paulo, Nova Cultural, ${ }^{4}$ 1991, p. 319.

${ }^{2}$ Albin Lesky, A tragédia grega, São Paulo, Perspectiva, 1990, p. 17. 
O cerne da peça de Eurípedes seria o conflito entre o masculino e o feminino, mais especificamente entre Jasão e Medeia, enfatizando também alguns dos problemas sociais da mulher ateniense, como o parto, o casamento, o dote, a fidelidade, o divórcio e a personalidade da mulher.

Contudo, vale salientar que na tragédia Medeia, Eurípedes ultrapassa as questões femininas, abordando no mesmo drama temas tensos e importantes para os gregos do quinto século, tais como a guerra, a paz e as relações com o estrangeiro.

Nesse sentido, ao retomar o século V a.C., observa-se a hegemonia da cidade de Atenas. O crescimento da cidade indicava que ela corria riscos, especialmente, nas relações com os estrangeiros, o que poderia levar a invasões ou guerras. Daí, a necessidade de ensinar a lógica da alteridade, o sentido que o outro, ainda distante, poderia dar aos atos e aos costumes dos atenienses.

O mundo ateniense era o masculino voltado, sobretudo, para um sistema considerado democrático. A mulher, excluída da participação social, não era agente no sistema, portanto, estava impossibilitada de subir ao kléos (glória).

Neste contexto, a tragédia de Medeia foi um divisor de águas, pois trouxe um novo dado à alteridade ateniense mal elaborada e pouco entendida. Eurípedes foi beber no mito de Jasão e dos Argonautas essa figura singular de mulher, meio divina e mágica, humana e passional, bem diferente dos padrões comportamentais estabelecidos para a época.

Com base nestas informações, este texto procura manifestar como a Medeia trágica conseguiu reforçar as regras da sociedade ateniense do período clássico, ao mesmo tempo em que desvendou a ira, a revolta, a vingança e o sofrimento.

\section{Jasão e Medeia: amor e ódio}

Reza o mito que Jasão casou-se com Medeia por esta ter ajudado o jovem rapaz a conquistar o velocino de ouro, cabeça de carneiro feita com fios de ouro, desejado pelo ambicioso rei Pélias, tio de Jasão e usurpador do reino de Iolco, terra natal do jovem herói. Por conseguinte, conseguir o velocino de ouro era a grande meta de Jasão: significava recuperar o trono aos descendentes de Éolo.

A bela princesa de Cólquida, a maga Medeia, se apaixona por Jasão, sendo capaz de realizar loucuras em nome do amor que dedica ao nobre herói. Entretanto, na peça, não há nenhuma menção de que Jasão teria se apaixonado de fato por Medeia. A feiticeira, possuidora do poder da cura, 
da magia, de certo modo era ignorada pelos rapazes de seu reino. Afinal, qual homem gostaria de casar-se com uma mulher que dominasse o poder da magia e em quem não se pudesse confiar?

Jasão foi esse homem. Casou-se com Medeia como condição imposta por ela caso lhe ajudasse a ganhar o velocino de ouro, símbolo de poder e grandeza para o mundo antigo. No entanto, a infidelidade de Jasão para com a esposa será o grande motivo da ira de Medeia.

Nesta perspectiva, pode-se argumentar, vulgarmente, que o amor se transformou em ódio. Segundo Bonnefoy:

A proteção de Hera ao herói se exerce através de Medeia, sem a qual Jasão não teria executado as tarefas impostas pelo rei de Cólquida. Filha de Eetes, confundem-se nela o poder de Hélio, o Sol, e as forças da noite. A princesa de Cólquida pertence a um elenco de mulheres versadas em magia e em poderes ocultos. Como Agamede, Hecamede ou Perimede, é imaginosa, dotada de uma inteligência solerte e astuciosa, graças à qual todas as forças, por maiores que sejam, são vencidas. Uma inteligência que age não por dissimulação ou embustes, visando à eficácia imediata, mas pelos meandros da magia, pelo emprego de ervas e de filtros, pela mobilização dos poderes da noite. Medeia é uma mulher com a força de mêtis, mas sua aliança com Jasão não é o casamento de Zeus com Mêtis, sua primeira esposa, que lhe outorgou o poder. As magias de Medeia abrem a Jasão o caminho para a conquista do velocino de ouro, talismã cuja perda significa para Eetes a destruição do poder real, mas que não confere de imediato ao herói o acesso ao poder, usurpado por Pélias. Sem Medeia, porém, Jasão jamais reporia o trono de Iolco nas mãos dos filhos de Éolo. A aliada, todavia, pode tornar-se uma inimiga tanto mais perigosa quanto para ela o casamento é algo contra a natureza. ${ }^{3}$

Apesar de extensa, a citação acima lembra que a figura de Medeia foi fundamental na conquista do velocino de ouro. O casamento com Jasão seria para ela a saída para uma nova vida, mais dinâmica e cheia de peripécias ao lado do homem amado. Todavia, por apresentar uma personalidade forte e, ainda, movida pelo ciúme, Medeia acabou subvertendo o papel da mulher 'apaixonada' e 'companheira'.

A Medeia de Eurípedes equivale a uma imagem oposta da mélissa ateniense, bem diferente da ateniense do século V a.C. A mélissa ateniense era excluída da sociedade, marginalizada e o seu papel secundário

3 Apud Junito de Souza Brandẽo, 'Jasão e os argonautas', in Mitologia grega 3, Petrópolis, RJ: Vozes, ${ }^{14} 2007$, p. 192. 
na sociedade machista a enquadrava na mesma categoria dos escravos. A mulher ateniense do século $\mathrm{V}$ é descrita, principalmente nas comédias de Aristófanes, como um ser fraco, histérico, incapaz de controlar seus impulsos e, ainda, sexualmente voraz, levando o homem à exaustão. A Medeia de Eurípedes se mostra o inverso do modelo feminino idealizado pelos atenienses.

Contudo, por ser uma estrangeira, Medeia não pode ser uma personagem feminina revolucionária. Apresentada quase sempre como transgressora, sua imagem não serviu de fato para mostrar a transgressão do feminino ou da esposa. Pelo contrário, a figura de Medeia acabou reforçando o modelo ideal de mulher sem grandes questionamentos.

Voltando ao drama de Medeia, com o perjúrio e a traição do esposo Jasão, ela se torna uma mulher melancólica, vingativa, transparecendo a todos o seu sofrimento diante de um futuro que ela jamais imaginara ao lado do homem amado.

O sentimento melancólico de Medeia é capaz de levá-la à loucura, atentando contra a vida dos próprios filhos para vingar-se do marido. Medeia clama por vingança, alude que a mulher foge à luta por medo, mas quando seu leito é ultrajado, não existe alma mais sedenta de sangue do que a da mulher. Assim, Medeia justifica seus atos por meio de um poder de persuasão e uma retórica veementes.

À luz da psicanálise de Freud ${ }^{4}$, o sentimento de perda nutrido por Medeia em relação a Jasão - já que ele se encontra prestes a casar-se com a princesa Glauce, filha do rei Creonte - evidencia a diminuição da autoestima da heroína, ao mesmo tempo em que reflete o sentimento de posse sobre o ser amado. Na melancolia, o sentimento de perda desloca-se para o outro; o objeto é perdido, mas a sombra se projeta sobre o eu; isso se torna a perda do eu. Logo, ao perder Jasão, Medeia sente-se sem rumo, perdese dentro de si mesma, haja vista não observar nenhuma outra forma de levantar-se diante do problema. No discurso de Medeia visualiza-se esse sentimento de perda: 'Que o fogo do céu caia sobre minha cabeça. Que a morte me traga alívio’ (v. 678) ${ }^{5}$.

Para a mulher, a perda do amor consiste num dos símbolos de castração, já delineados por Freud. O homem, elemento fálico possuidor do

\footnotetext{
${ }^{4}$ Sigmund Freud, 'As neuropsicoses de defesa', in Edição Standard das Obras Psicológicas Completas 3, Rio de Janeiro, Imago, 1976.

${ }_{5}^{5}$ EuríPedes, Medeia, trad. Miroel Silveira e Junia Silveira Gonçalves, Rio de Janeiro, Victor Civita, 1982, v. 678. Informar-se-á, a partir de agora, apenas os versos da referida obra de Eurípedes.
} 
'ter', depende intensamente do 'ser' mulher, que se sustenta, por sua vez, duplamente no amor e no ódio: ser amada é igual a ser o falo. Igualmente, é ter poder, é possuir o devido reconhecimento dos outros ${ }^{6}$. Quando Jasão abandona Medeia, esta deixa de ser reconhecida como mulher de Jasão, como o elemento de posse, e passa a ser apontada como a primeira esposa, aquela que fora trocada ou rejeitada.

Neste sentido, Medeia perde o seu próprio eu, pois vê em Jasão o amor incondicional. Assim, o que resta à heroína trágica é a morte: 'Sim, lamento o crime que vou praticar; porém, maior do que minha vontade é o poder do ódio, causa de enormes males para nós mortais!' (v. 799) morte em várias instâncias, morte como vingança, como punição e como sofrimento. Então, matar os filhos representa a atitude perante o ódio moral para Jasão. Assim:

a tônica de Medeia é o ódio sobre-humano em que se transforma o amor da heroína por Jasão, quando este a repudiou para casar-se com a filha do rei da região que os acolhera. [...] A peça evolui de uma Medeia abatida pelo repúdio do marido, esposa traída que definhava no leito e nem sequer levantava as pálpebras para abrir os olhos, aparentemente conformada com a sorte, para uma mulher animada por um terrível desejo de vingança e extermínio, que não se detinha diante do infanticídio, como vindita extrema para o aniquilamento completo do marido perjuro?

Desse modo, ferida pela infidelidade de Jasão, Medeia deseja causar a mesma dor àquele que um dia ela amou loucamente. Matar os filhos para ferir o outro. 'Estremeço do pensamento do que me restará fazer: matarei meus filhos. Não tenho outro meio para dilacerar o coração do pai deles...' (v. 813). Além disso, para Freud, a vontade filicida indica uma preocupação excessiva com a saúde ou com atitudes de hipermedicar os filhos ${ }^{8}$. No pensamento de algumas mulheres 'medeianas' há um transtorno avalizando que, agindo com brutalidade ou agressividade, elas vão evitar que os filhos sofram e, assim, irão protegê-los de todo o mal.

Embora neste trabalho não se objetive realizar psicocrítica ou uma abordagem psicanalítica da personagem Medeia, julga-se por bem dia-

\footnotetext{
${ }^{6}$ Sigmund Freud, 'A sexualidade feminina', in Edição Standard das Obras Psicológicas Completas 21, Rio de Janeiro, Imago, 1976.

${ }^{7}$ Mário da Gama Kury, Introdução à tragédia Medeia, Rio de Janeiro, Jorge Zahar, 1991, p. 15.

${ }^{8}$ Sigmund Freud, 'A sexualidade feminina'...
} 
logar com algumas das leituras de Freud e Lacan, a fim de que se possa argumentar sobre a ação filicida desta heroína trágica chamada Medeia. Tal ação, insensata aos olhares de uma avaliação pública, versa sobre um desespero (in)comum aflorado em muitas mulheres que agem de forma passional. Esse desejo, considerado sádico - o de ferir os próprios filhos para maltratar o outro, ou seja, fazer o marido experimentar o mesmo sofrimento que ela (mulher) suportou ao ser rejeitada -, nada mais é do que um pensamento obsessivo que penetra a cabeça de muitas mulheres ${ }^{9}$.

Lacan, ao contrário de Freud, diz que este tipo de comportamento tão impróprio de alguns é decidido conforme as atitudes do outro. Então, o destino para se cumprir precisa das atitudes do outro. Atitudes que marcam o corpo do sujeito com palavras que designam suas várias partes, o mortificam e tornam o corpo significante ${ }^{10}$.

Assim, Medeia insinua que todas as mazelas só aconteceram por culpa de Jasão. Por meio da retórica e do poder de argumentação e de autodefesa, ela tenta livrar de si toda a culpa pela morte dos filhos, colocando em Jasão a responsabilidade maior de tamanha desgraça: 'os deuses sabem a quem cabe toda a culpa' (v. 1372).

Em síntese, não há como imaginar o mito de Medeia sem o assassinato dos filhos. Tal fato preconiza a tímoria e o páthos da heroína de Eurípedes, o amor que nem sempre vence o ódio.

\section{Tímoria e Páthos em Medeia, de Eurípedes}

A heroína trágica Medeia comete sua hýbris (desmedida do herói) quando transforma a magia, dom que possui, em instrumento de vingança (tímoria). Como sua condição era de feiticeira, utilizou-se da morte para atingir seus objetivos e ferir Jasão por meio da morte dos dois filhos: Feres e Mérmero. A morte das crianças foi a vingança de Medeia contra Jasão.

Mas, o fato de Medeia matar os filhos acaba encobrindo o descaso de Jasão para com a família: a real causa da tragédia foi a traição de Jasão. Ele esqueceu o quanto a princesa de Cólquida se arriscou ao ajudá-lo a conquistar o velocino de ouro - entregou-se a Jasão antes do casamento, matou seu irmão Aspirtis, fugiu de sua pátria, tudo em nome do amor que nutria por Jasão.

\footnotetext{
9 Sigmund Freud, 'Obsessões e fobias', in Edição Standard das Obras Psicológicas Completas 3, Rio de Janeiro, Imago, 1976.

${ }^{10}$ Sigmund Freud, 'As neuropsicoses de defesa', in Edição Standard das Obras Psicológicas Completas 3, Rio de Janeiro, Imago, 1976.
} 
A reação de Jasão centra-se na culpa de Medeia, pois é bem mais fácil julgar um crime doloso do que apontar os erros de um esposo infiel. Assim, Jasão acusa Medeia:

Monstro! Mulher de todas a mais odiada por mim e pelos deuses, pela humanidade! Tiveste a incrível ousadia de matar tuas crianças com um punhal, tu, que lhes deste a vida, e também me atingiste mortalmente ao me privar dos filhos! (v.923)

A atitude de Medeia não só feriu passionalmente o esposo infiel; também foi um golpe fatal sobre o kléos do qual era portador. Na antiga sociedade grega, a glória ou notoriedade de um indivíduo era perpetuada pela sua descendência, tornando-se maior com o suceder dos séculos. Logo, privar Jasão de descendência era usurpar-lhe a glória futura. Seu nome não mais soaria na boca de seus descendentes, que diriam: 'nosso pai Jasão que trouxe o velo da Cólquida'. Ao matar os filhos, Medeia tirava do príncipe de Iolco tudo aquilo que lhe dera: descendência, fama e glória. Sua mágoa de mulher traída não apenas feria o alvo de sua fúria, mas varria todos os rastros lustrosos que o futuro poderia conceder-lhe.

Medeia simboliza a mulher abandonada, mas em nenhum momento ela se esquiva ou nega ter matado os filhos, salientando que o faz contra Jasão. Assim também, nos versos 181 e 184, Medeia lastima ter seguido Jasão e abandonado sua pátria e sua família; por isso, matando as crianças, Medeia acredita que estaria evitando que elas sofressem os ataques dos inimigos, já que seriam sempre vistos como estrangeiros. Medeia amava os filhos, seu afeto é comprovado em vários versos da tragédia; pode-se perceber que o ódio ou o ciúme a tenham deixado insana, mas é inegável que ela os amava. Em um trecho da peça em que se assemelha a um monólogo, Medeia diz: 'Esquece por momentos de que são teus filhos e depois chora, pois lhes queres tanto bem mas vai matá-los! Ah! Como sou infeliz!' (v. 840)

Nesta direção, seria a morte das crianças um tipo de proteção aos filhos? Não seriam eles imortais, por isso Medeia os havia sacrificado? $\mathrm{Na}$ verdade, muitas versões circundam o mito de Medeia, umas depõem a favor do lado divino da heroína. Porém, como uma deusa cometeria tal atrocidade contra os seus próprios filhos? Talvez se ela fosse mesmo imortal, justificaria o fato de ter matado os filhos: eles também seriam imortais. Contudo, uma deusa imortal jamais cometeria tal atrocidade para com seus filhos.

No entanto, pode-se visualizar que o grande estimulador da vingança foi o ciúme de Medeia. Ao mostrar a dor e o desespero, ocasionados pela 
traição do marido, Eurípedes exibe o paradigma de uma sociedade em que a mulher não tem um apoio legal; traída, ela teria que aceitar e viver como estrangeira, humilhada e maltratada pelos outros e talvez distante dos filhos, já que a lei grega não conferia à mulher poder sobre os filhos. Assim, Medeia estava legalmente desamparada diante de seu infortúnio e representada como a mulher 'vingadora'.

O instinto mal de Medeia não está apenas em seus atos falhos, mas, sobretudo, no modo como ela acaba empregando o dom da cura que lhe fora ofertado pelos deuses. Por meio das ervas venenosas, Medeia mata o rei Pélias, a princesa Glauce, o rei Creonte e os próprios filhos. A poção venenosa que ceifou a vida da princesa Glauce era tão poderosa que contribuiu, inclusive, para a morte do rei Creonte que fora socorrer a filha:

\section{Se ela receber}

Os ornamentos e com eles enfeitar-se,

Perecerá em meio às dores mais cruéis

e quem mais a tocar há de morrer com ela,

tão forte é o veneno posto nos presentes. (vv. 898-902)

Portanto, Medeia contraria muitos dos padrões da pólis ateniense. Então, esse saber da cura que ela possuia mudou o rumo de sua história. A bela princesa de Cólquida, Medeia, arriscou muito com suas atitudes, mudando a sua história; uma mulher estrangeira, feiticeira, ativa, perspicaz, passional, que leva sua paixão às últimas instâncias, acima até mesmo do amor maternal. Assim como diz Jasão: 'Não há mulher grega que tenha ousado isso' (v. 915).

Medeia ousou, regida pelo diferente que a levou ao páthos, ao sofrimento. Ela se aventura mais uma vez quando fala da sua diferença em relação ao masculino, especialmente para uma sociedade altamente machista, que certamente lhe julgará:

De todos os que têm alma e pensamento, nós, mulheres, somos a criatura mais infeliz. Primeiro, é preciso, com o máximo de bens, comprar um marido e tomar o déspota de nossos corpos. Esse mal é mais doloroso do que o próprio mal. [...]

Dizem que vivemos uma vida sem perigos em casa, enquanto eles guerreiam com a lança; e pensam mal, pois preferiria eu três vezes lutar com o escudo a parir uma única vez. (vv.230-251) 
A retórica de Medeia e o seu discurso abriram muitas imagens para um destino que, diante dos atos falhos da heroína, possibilitou o encontro a um caminho sem volta. Assim acontece com Medeia.

A dualidade da heroína trágica Medeia põe em xeque sua qualidade mais insana: a de agir e falar quando a sociedade exige que ela se esconda e se cale. Por isso, mesmo diante do infortúnio e das mazelas, Medeia não perdoa a traição, o páthos é o caminho sem volta, a dor e a punição para o Eros sem medida, quando se ama mais ao outro do que a si mesmo.

TitLE. Timor and pathos in Medea, by Euripides

ABSTRACT. This paper presents some considerations about the Timor (revenge) and pathos (suffering) in the tragedy Medea, by Euripides, written around the fifth century BC The image of Medea is immortalized for readers melancholy woman, who suffers because to abandon the man she loved, monstrous, vengeful, reaches the height of his despair when he kills his own children to smite the unfaithful spouse. Jealousy gives the tone to the filicide, leading to Timor and, accordingly, the pathos. Rejected by the beloved, the woman symbolizes Medea impulsive, passionate, which punishes the husband dramatically by committing perjury. Medea tragic woman flees to the standards of the time of the Athenian Euripides, this fact suggests that it would not be the ideal kind of wife. The tragedy focused the Athenian herald the period of their possible condition to become Greek: to find a reverse path of glory, the risk of becoming as barbaric Medea, a reflection of revenge and suffering in the face of misfortune. KeYwords. Medea; tragedy; revenge; suffering. 
Titre. Timor et pathos dans Médée, d'Euripide

RÉsumÉ. Cet article présente quelques considérations sur l'Timor - la vengeance - et du pathos - la souffrance - dans la Médée tragédie, d'Euripide, écrite autour de la $\mathrm{V}^{\mathrm{e}}$ siècle avant J.-C. L'image de Médée est immortalisé pour la femme lecteurs mélancoliques, qui souffre à cause d'abandonner l'homme qu'elle aimait, monstrueuse, vengeresse, atteint la hauteur de son désespoir quand il tue ses propres enfants pour frapper l'épouse infidèle. Jalousie donne le ton à l'infanticide, conduisant à Timor et, en conséquence, le pathos. Rejeté par la bien-aimée, la femme symbolise Médée impulsif, passionné, qui punit le mari de façon spectaculaire en parjure. Médée fuit femme tragique aux normes de l'époque de la Euripide athénienne, ce fait donne à penser qu'il ne serait pas le genre idéal de femme. La tragédie a attiré l'Athénien héraut de la période de leur état possible de devenir grecs: pour trouver un chemin inverse de la gloire, le risque de devenir aussi barbare Médée, un reflet de la vengeance et la souffrance dans le visage du malheur.

Mots-CLÉs. Médée; la tragédie; la vengeance; la souffrance. 